\title{
Evaluation of Remaining Dentin Thickness (RDT) Following Tooth Preparation for All Ceramic Crowns - An in Vitro Study.
}

\author{
Dr. S. Seyedasharafali,MDS ${ }^{1}$, Dr. Suma Karthigeyan, MDS $^{2}$, J.Sankar, MDS ${ }^{3}$, \\ R. Madhan, MDS $^{4,}$ Dr. R. Krishnaraj,MDS ${ }^{5,}$ Dr. Kalarani,MDS ${ }^{6}$
}

\begin{abstract}
Statement of the problem: Enormous tooth substance is removed to receive all ceramic restorations which in turn affects the vitality of the tooth.

Purpose of the Study: The purpose of this study is to measure the remaining dentin thichness (RDT) following tooth reduction for all ceramic crowns in freshly extracted premolars and to correlate RDT to Pulpal response. Materials and Methods: 45 freshly extracted human permanent maxillary first premolar teeth, scheduled to be removed for orthodontic purpose were selected from patients ranging from 16 to 30 years of age. The Samples were grouped by Three axial surfaces (Mesio Buccal (MB),Buccal (B) and and Disto-Buccal (DB) Axial Surfaces), Three Age Groups (G1- 15 to 20, G2 - 21 to 25, and G3-26 to 30) and finally by sex. Tooth preparation was done following standard guidelines for metal free restorations $(1.2 \mathrm{~mm}$ radial shoulder and as minimal taper clinically possible) by a single operator. RDT was measured in the three axial surfaces (Buccal, Mesio Buccal and Disto Buccal) using a Stereomicroscope and Image Analysis Software. The results were statistically analyzed using $f$-test (one way anova). Among the three surfaces Disto buccal showed the least RDT least RDT (0.97mm) followed by mesio-buccal $(1.55 \mathrm{~mm})$ and buccal surface $(2.11 \mathrm{~mm}) . \quad P<0.001$.
\end{abstract}

Keywords: RDT, Remaining Dentin, Effective Dentin, Preparation for All ceramics

\section{Introduction}

Increase in demand for esthetic restorations has resulted in the development of many all ceramic systems $^{1,2,3,4,5}$. To achieve physiologic crown contours, structural durability and enhanced esthetics it is recommended to reduce $1.2 \mathrm{~mm}$ to $2 \mathrm{~mm}$ of enamel and dentin circumferentially to provide room for the core and veneering porcelains ${ }^{5,6,7}$. Pulpal injuries caused by tooth preparations are a major concern in Prosthodontics and a high number of vital abutment teeth ended up in endodontic therapy following prosthesis cementation ${ }^{8,9,10,11,12 \text {, }}$.

The distance between the preparation and the pulp referred to as remaining dentine thickness, has long been recognized as an important factor influencing tooth vitality ${ }^{13,14,15}$. Extensive preparations with minimal remaining dentine thickness, leaves the pulp tissue less protected from preparation injuries and chemical activities of dental materials. The remaining dentin thickness estimated to be necessary for the protection of the dental pulp has changed over the years. A minimum of $2 \mathrm{~mm}$ has been reported to be a critical factor in determining the pulp response and to maintain pulp vitality, and a very small variation in the remaining dentin thickness has shown significant influence on the pulp reactions. RDT has also been reported to have significant influence on the fracture resistance of the prepared teeth and the bond strength of the luting agents.

During treatment, it is often difficult for the dentists to decide how much dentin is left over the pulp. This study was conducted to evaluate the amount of remaining dentin thickness, a key factor in preserving pulp vitality, following tooth preparation for all ceramic restorations.

\section{Material and methods}

This study was done at Rajah Muthiah Dental College and Hospital, Annamalai University, Tamilnadu, to evaluate the Remaining Dentine Thickness in extracted maxillary premolars using Stereomicroscope and Image Analysis Software, following tooth preparation for All Ceramic Restorations .

Forty five samples were selected for this investigation. All the test samples met the following criteria:

1. Maxillary first premolar teeth, extracted for orthodontic purpose,

2. The teeth should be free of caries, fillings, attrition, abrasion and erosions

3. Age of the individual should be between the range of 16 to 30 years .

Test Samples were grouped by

1. Three axial surfaces (Mesio-Buccal, Buccal, Disto-Buccal axial surfaces),

2. Three age groups: Group I-15to20years ( 13 samples), Group II- 21 to 25 years (19 samples), Group III-25 to 30 years (13 samples), and finally

3. Two groups by sex (Male -23 samples and Female -22 samples). 
All the 45 test samples were cleaned in hydrogen peroxide and each sample mounted in Poly Vinyl Chloride (PVC) cylinder, measuring 20mm height and $13 \mathrm{~mm}$ in diameter using autoploymerizing resin (DPI , India) (fig1). The teeth were sectioned midway using a Diamond Disc (Diameter 20mm, Thickness 0.3mm,

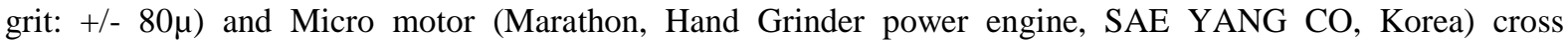
sectionally in a mesio-distal direction, to expose the coronal portion of the coronal pulp (fig. 2). After sectioning the tooth, tooth preparation was done for all ceramic restoration based on standard guidelines using a conta angled airotor handpiece and $1.2 \mathrm{~mm}$ flat ended tapered diamond (Mani Burs) . The preparation consisted of $1.2 \mathrm{~mm}$ radial shoulder margin and 6 to 10 degree axial taper.. All the preparations were done by a single operator to simulate clinical conditions and to avoid inter-operator variability .

Distance between the outer surface of the preparation and exposed coronal pulp chamber considered as Remaining Dentine Thickness was measured in the three axial surfaces (buccal, mesio-buccal, and disto-buccal) using Stereomicroscope (Meiji-Japan MIL 7100 20x Magnification) and Image Analysis Software (Metal Vision MVLx1.0) (fig6). The measurements obtained were statistically analyzed .

\section{Results}

The values obtained were statistically analyzed using $\mathrm{f}$ - test ( one way anova). The results of this study show that there is a statistically significant difference $(\mathrm{P}<0.001)$ among the three surfaces. Disto-buccal surface had the least RDT $-0.97 \mathrm{~mm}$ followed by mesio-buccal $-1.55 \mathrm{~mm}$ and buccal surface $-2.11 \mathrm{~mm}$. (Table1) (fig.3) .

On comparing the age factor, in the Mesio Buccal surface, Group I(15-20yrs) had the least RDT $1.38 \mathrm{~mm}$ (mean), followed by Group II (21 - $25 \mathrm{yrs}) 1.53 \mathrm{~mm}$ and Group III (25-30 yrs) had the maximum RDT of $1.75 \mathrm{~mm}$. In the Buccal surface, Group I (15- $20 \mathrm{yrs})$ \& Group II (25 - 30 yrs) had similar RDT (1.96 $\mathrm{mm} \& 1.95 \mathrm{~mm}$ ) and group $3 \mathrm{had}$ high RDT $2.49 \mathrm{~mm}$. In the Disto-Buccal surface, all the three age Groups had similar RDT ( group I and group II - 0.95mm RDT \& Group III - 0.97mm RDT).(Table .2)(fig.4).

In males, the disto-buccal surface had least RDT $1.02 \mathrm{~mm}$ followed by mesio-buccal $1.46 \mathrm{~mm}$ and buccal $2.17 \mathrm{~mm}$. Females had RDT of $0.9 \mathrm{~mm}$ in Disto-Buccal surface, $1.46 \mathrm{~mm}$ in mesio buccal surface , and $2.04 \mathrm{~mm}$ in the buccal surface RDT (Table-3).(fig.5)

\section{Discussion}

The importance of remaining dentin thickness (RDT) in maintaining the vitality of the tooth following tooth preparation has long been recognized. Stanley ${ }^{17}$ reported that a $2 \mathrm{~mm}$ of RDT is necessary to protect the pulp. P. E. Murray et $\mathrm{al}^{15}$ reported that a RDT of $0.5 \mathrm{~mm}$ or greater is necessary to avoid evidence of pulp injury. Most of the studies signifying the importance of RDT were done in intracoronal restorations. The number of open tubules in intracoronal preparations are comparatively less necessitating the evaluation of RDT in extracoronal preparations.

In this study a $1.2 \mathrm{~mm}$ radial shoulder margin was prepared as recommended by various studies and the recommendations of the manufacturers. All preparations were done by a single operator in extracted maxillary first premolar in the age group of 15 to 30. The thickness of remaining dentin was evaluated at three surfaces Buccal, Mesio -Buccal and Disto Buccal. The results of the study showed that the Buccal surface having the highest average of RDT $(2.11 \mathrm{~mm})$ followed by Mesio-Buccal surface ( RDT - $1.55 \mathrm{~mm}$ ) and the Disto-Buccal surface ( RDT - 0.95mm). R.Polansky et $\mathrm{al}^{18}$ measured RDT after preparation of a shoulder in the extracted molars and premolars. Premolars had an average maximum RDT of $0.7 \mathrm{~mm}$, and average minimum RDT of 0.46 $\mathrm{mm}$.

On comparing the RDT according to age, Group1 (15-20 years of age) had the least Remaining Dentine Thickness, Group 2 (21 -25 years) had moderate RDT and group 3(25 - 30 years)had the maximum RDT. This difference is statistically significant ( $\mathrm{P}$-value $<0.001$ ). This is in accordance to the fact that the dentin thickness increases with age ${ }^{19}$.

On comparing Remaining Dentine Thickness according to sex, the female group had more RDT than male. The results are also statistically significant $(\mathrm{p}<0.01)$.

It is recommended to use esthetic resin luting cements for esthetic all ceramic restorations. The biocompatibility of resin cements in deep preparations is still an area of debate. Sergie bouillaguet et al ${ }^{19}$ in their study had shown that the decrease in dentin thickness increased the risk of acute cytotoxicity. J.Hebling et $\mathrm{al}^{20}$ reported the pulpo-dentin complex response to adhesive system application in deep tooth preparations, and showed the inverse relationship between RDT and pulp inflammatory response. Intensity of pulp response increased as RDT decreased. $\quad$ A.Hamid et $\mathrm{al}^{21}$ showed that dentine thickness variation clearly affected both diffusion rates and cumulative release of the two trace molecules (HEMA\& TEGDMA). Decreasing dentine thickness markedly increased pulp ward diffusion rate and total diffusion of both monomers from bonding-resin restorations. It is very likely therefore that substantial reduction of dentine thickness will reduce the protective effect of dentine for both HEMA and TEGDMA. Kessiri Wisithphrom et al $^{22}$ reported that the 
pulp vitality was reduced by the Remaining Dentine Thickness of the tooth preparations, whereas the other variables, including the type of restorative materials, had little effect.

The influence of RDT on the bond strength of luting agents to dentin has been reported by many authors . The bond strength to dentin signficantly decreased when the pulp chamber is approached . L Perinka et $\mathrm{al}^{23}$ investigated the relationship between the tensile bond strength (TBS) and remaining dentin thickness (RDT).The Tensile bond strength varied depends on the RDT. Satoshi Inoue et al ${ }^{24}$ reported that the microtensile bond strength of glass ionomer adhesive to dentin significantly improved when the RDT increased. Several reasons for this bonding have been advocated: (1) the area of intertubular dentin available for micromechanical retention through hybridization decreases when the diameter and the number of dentinal tubules increases closer to the pulp (2) the dentin permeability increases if an adhesive system is used that completely removes the smear layer and unplugs the tubules through acid etching ; (3) the pulpal pressure and intrinsic wetness increases and/or (4) calcium concentration of deep dentin is lower than that of supercial dentin. On the contrary, self-etch adhesives have been presented with bond strength data unaffected by RDT or dentin depth . This must be largely attributed to the fact that smear debris is commonly kept on intertubular dentin or within the dentinal tubules. ${ }^{25}$

As RDT has been shown to have a significant influence on tooth vitality and the bond strength of cemented restorations, every effort should be made to preserve RDT. Tooth preparation should be performed based on the Pulpal morphology rather than performing a uniform reduction all around. Selection of ceramic systems should be based on the clinical needs rather than applying the same system for all situations. This study was performed in maxillary first premolars and further studies are recommended on other permanent teeth also.

\section{Conclusion}

Within the limitation of this study, the following conclusions can be drawn.

- Disto-buccal surface of the human permanent maxillary permanent first premolar teeth has least RDT . Care must be taken to keep the reduction to a minimum, while reducing the tooth structure in this region.

- Buccal surface has maximum RDT followed by mesio buccal and distobuccal.

- Age shows a significant influence on RDT. Young individuals have minimal RDT following tooth preparations.

- There was no significant difference in RDT among male and female.

\section{References}

[1]. Isabelle 1. Denry Recent advances in ceramics for dentistry. Crit Rev Oral Biol 1996: 7(2):134-143

[2]. Sarah Pollington, Richard van Noort. An update of ceramics in dentistry: International Journal of Clinical Dentistry 2009: 2( 4) :283- 307

[3]. A.J. Raigrodski, DMD, Contemporary all-ceramic fixed partialdentures: a review, Dent Clin N Am 48 (2004) 531-544

[4]. Kelly JR, Nishimura , Campbell SD: Ceramics in dentistry: historical roots and current perspectives. The Journal of prosthetic dentistry. 1996 Jan;75(1):18-32.

[5]. Budhathoky, Chen Lei; Essential factors in success of all-ceramic restoration. Journal of Nepal Dental Association2010;11(2);199203.

[6]. S. F. Rosenteil, M. F. Land, J. Fujimoto: Contemporary fixed Prosthodontics, ed. 3, Mosby ,2001, P 167.H

[7]. T.Schillingberg :Fundamentals of fixed Prosthodontics, ed. 3, quintessence

[8]. Langeland K, Langeland LK. Pulp reactions to crown preparation,impression, temporary crown fixation, and permanent cementation.J Prosthet Dent 1965;15:129-143.

[9]. Bergenholtz G, Nyman S. Endodontic complications following periodontal and prosthetic treatment of patients with advanced periodontal disease. J Periodontol 1984;55:63-68

[10]. Assessment of the periapical and clinical status of crowned teeth over 25 years. J Dent 1997;25:97-105.

[11]. Walton JN, Garner FM, Agar JR. A survey of crown and fixed partial denture failures: Length of service and reasons for replacement. J Prosthet Dent 1986;56:416-421.

[12]. Reuter JE, Brose MO. Failures in full crown retained dental bridges. Br Dent J 1984;157:61-63.

[13]. Peter E.Murray (2000, JD), I .About, Philip. J.Lumley, J.C. Franquin, M.Remusat, A.J.Smith; Human odontoblast cell numbers after dental injury. Journal of Dentistry 2000; volume 28; page no 277-285.

[14]. Peter E.Murray,Phillip J.Lumley and Anthony J.Smith: Preserving the vital pulp in operative dentistry:3 thickness of remaining cavity dentine as a key mediator of pulpal injury and repair responses. Dental Update 2002:29:172-178

[15]. Peter.E.Murray(2003,IEJ), L.J.Windsor, A.J.Smith, I.A.Mjor: Remaining dentine thickness and human pulp responses.International Endodontic Journal 2003;36;33-43

[16]. Florian Wegehaupt, Herbert Bete, Nicole Solloch, Ulrike Musch, Annette Wiegand, Thomas Attin: Influence of cavity linining and remaininig dentine thickness on the occurrence of postoperative hypersensitivity of composite restorations. Journal of Adhesive Dentistry 2009:11:137-141.

[17]. Stanley HR. Pulp irritation tests: restorative materials influencing dentin and pulp. In: Stanley HR, editor. Toxicity testing of dental materials, Boca Raton, FL: CRC Press, 985. p. 91-121.

[18]. R. Polansky, G Arnetz, M. Haas, C.Keil, G.Wimmer, M.Lorenzoni; Residual Dentin Thickness after 1.2mm shoulder preparations for Cerec Crowns. International journal of computerized dentistry 2000;3(4);243-258.

[19]. Serge Bouillaguet, John C.Wataha, Carl T.Hanks, Bernard Ciucchi, Jacques Holtz; In vitro cytotoxicity and dentin permeability of HEMA. JOE 1996;22(5); 244-248.

[20]. J.Hebling, E.M.A. Giro, C.A.S.Costa; Human pulp response after an adhesive system application in deep cavities. Journal of Dentistry 1999;27;557-564. 
[21]. A.Hamid, W.R.Hume; The effect of dentine thickness of resin monomers in vitro. Journal of Oral Rehabilitation 1997;24;20-25.

[22]. Kessiri Wisithphrom, Peter E.Murray, Imad Abot, L.J.Windsor; Interactions between cavity preparation and restoration event and their effects on pulp vitality. The International Journal of Periodontics and Restorative Dentistry 2006;26;596-605.

[23]. L Perinka, H Sano, H Hosoda: Dentin thickness, hardness, and Ca-concentration vs bond strength of dentin adhesives. Dental Materials 1992;8;4;229-233.

[24]. Satoshi Inoue, Bart Van Meerbeek, Yasuhiro Yoshida, Paul Lambrechts, Guido Vanherle, Hidehiko Sano; Effect of Remaining Dentin Thickness (RDT) and the use of conditioner on micro-tensile strength og glass-ionomer adhesive. Dental Materials 2001;17;445-455

[25]. Tao L, Pashley DH. Shear bond strengths to dentin: effects of surface treatment, depth and position. Dent Mater 1988;4:371 \pm 8 .

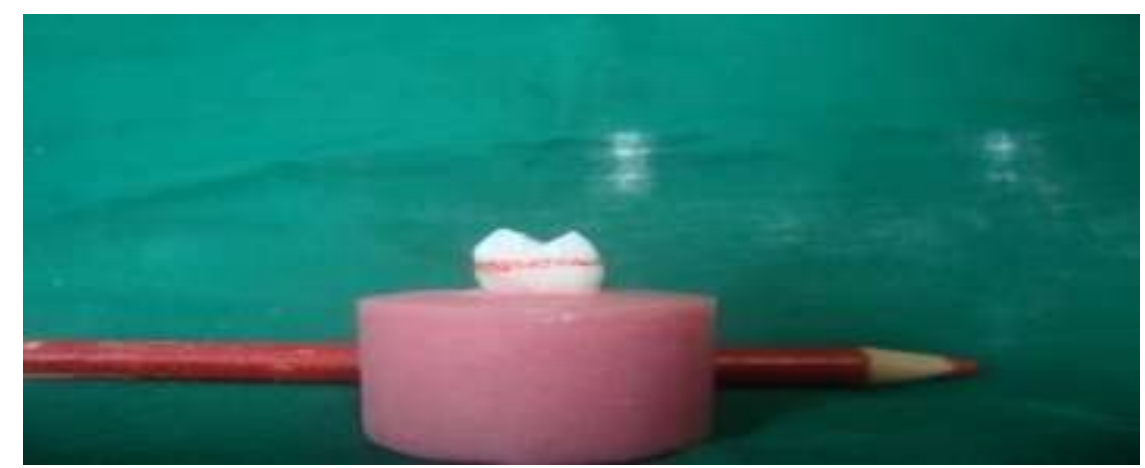

Fig. 1.Teeth mounted in autopolymerizing resin.

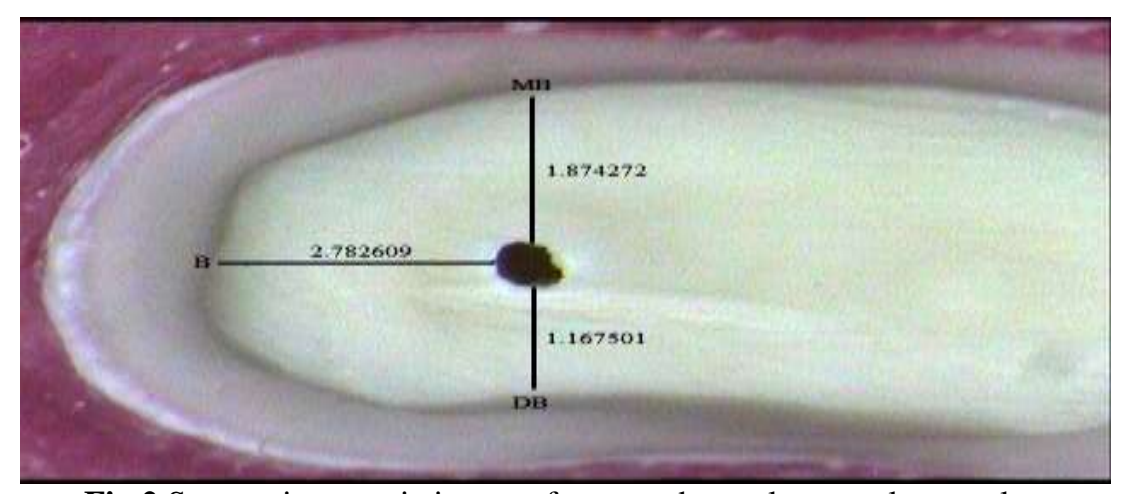

Fig.2.Stereomicroscopic image of prepared samples samplessamples

\section{Surface comparison}

\section{Results}

\begin{tabular}{|c|c|c|c|c|c|c|}
\hline Group & $\mathbf{N}$ & Mean & SD & Minimum & Maximum & P-value \\
\hline MB & 45 & 1.55 & 0.46 & 0.596 & 2.567 & \multirow{3}{*}{$\begin{array}{l}0.001 \\
\text { Significant }\end{array}$} \\
\hline B & 45 & 2.11 & 0.68 & 0.612 & 3.329 & \\
\hline $\mathrm{DB}$ & 45 & 0.97 & 0.26 & 0.071 & 1.397 & \\
\hline
\end{tabular}

Table-1: The recorded values of RDT for the three surfaces. (MB - Mesio Buccal, B - Buccal, DB - Disto Buccal)

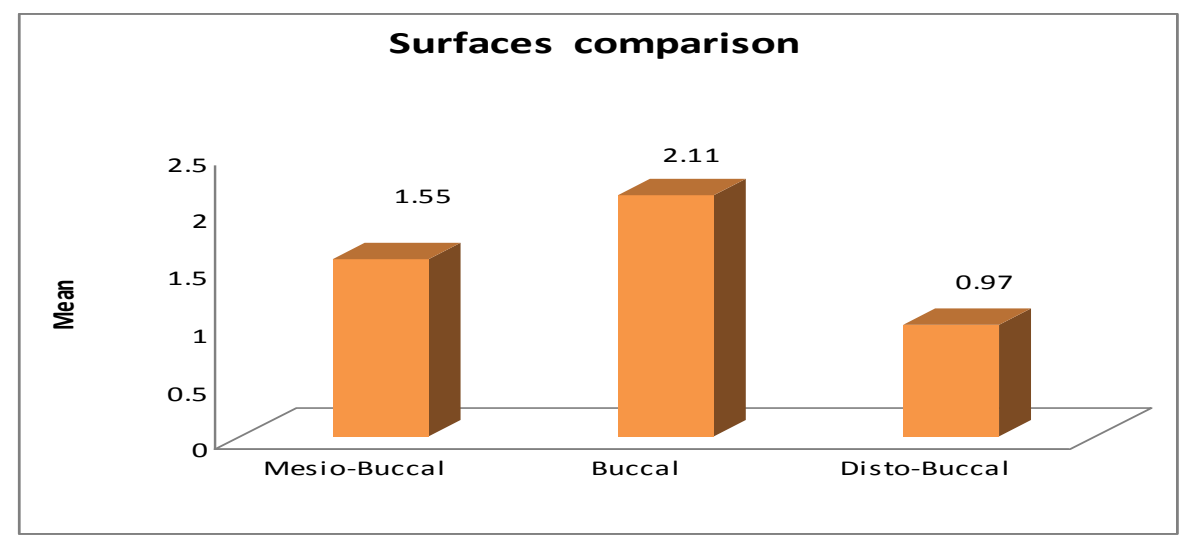


Fig. 3. Graph showing the comparision of RDT in the three surfaces

\begin{tabular}{|l|l|l|l|l|l|l|l|l|}
\multicolumn{9}{|c|}{ Table-2 } \\
\hline \multirow{2}{*}{ Age } & \multirow{2}{*}{$\mathbf{N}$} & \multicolumn{2}{|l|}{ Mesio - Buccal } & \multicolumn{1}{l|}{ Buccal } & \multicolumn{2}{l|}{ Disto-Buccal } & \multirow{2}{*}{ p-value } \\
\cline { 3 - 8 } & & Mean & SD & Mean & SD & Mean & SD & \\
\hline $15-20$ & 13 & 1.38 & 0.40 & 1.96 & 0.76 & 0.95 & 0.25 & $0.001 \mathrm{~S}$ \\
\hline $21-25$ & 19 & 1.53 & 0.46 & 1.95 & 0.60 & 0.97 & 0.22 & $0.001 \mathrm{~S}$ \\
\hline $25-30$ & 13 & 1.75 & 0.46 & 2.49 & 0.59 & 0.96 & 0.32 & $0.001 \mathrm{~S}$ \\
\hline
\end{tabular}

$\mathrm{S}-$ Significant

Table-2: The recorded values of RDT for the three age groups.

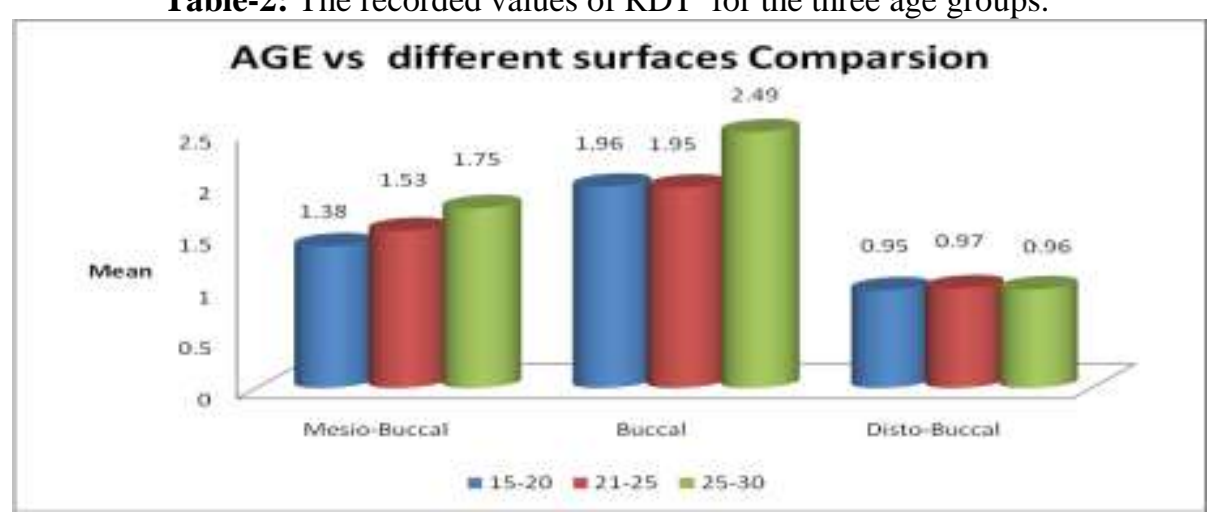

Fig. 4 Graph showing the comparision of RDT in the three age groups

Table-3 Gender

\begin{tabular}{|l|l|l|l|l|l|l|l|l|}
\hline $\begin{array}{l}\text { Gende } \\
\text { r }\end{array}$ & \multirow{2}{*}{$\mathbf{N}$} & \multicolumn{4}{|l|}{ Mesio-Buccal } & \multicolumn{2}{l|}{ Buccal } & \multicolumn{2}{|l|}{ Disto - Buccal } & \multirow{2}{*}{ p-value } \\
\cline { 3 - 9 } & & Mean & SD & Mean & SD & Mean & SD & \\
\hline Male & 23 & 1.64 & 0.49 & 2.17 & 0.65 & 1.02 & 0.24 & $0.01 \mathrm{~S}$ \\
\hline Female & 22 & 1.46 & 0.40 & 2.04 & 0.71 & 0.90 & 0.27 & $0.01 \mathrm{~S}$ \\
\hline
\end{tabular}

S- significant

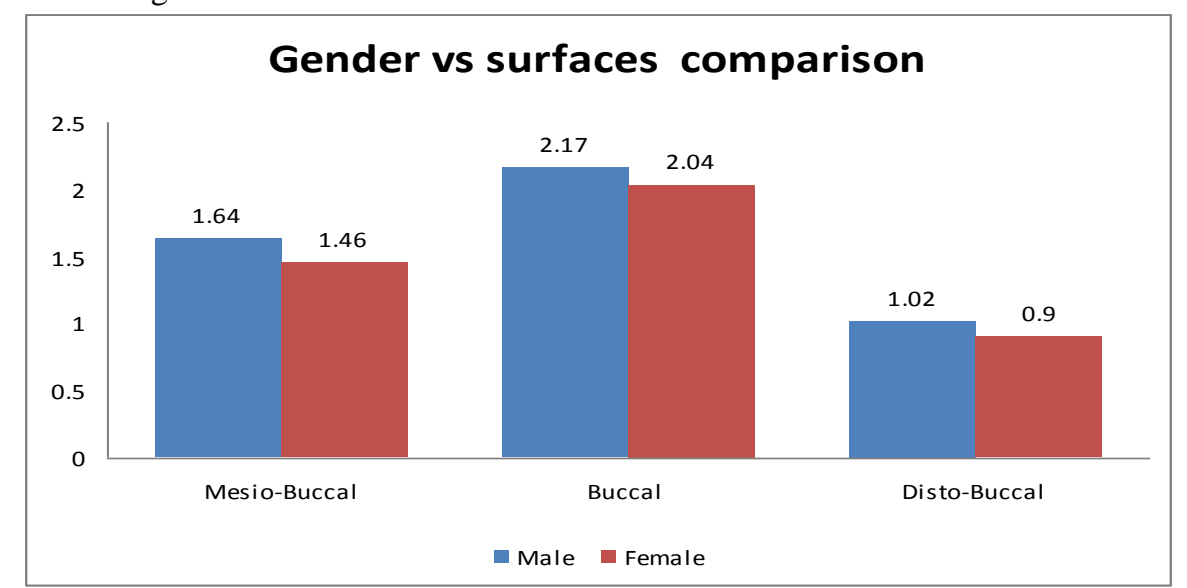

Fig. 5 Graph showing the comparision of RDT among the gender. 